\title{
Preparation of high-capacity magnetic polystyrene sulfonate sodium material based on SI-ATRP method and its adsorption property research for sulfonamide antibiotics
}

\author{
Huachun Liu ${ }^{1,2}$, Bolin Gong ${ }^{1,2^{*}}$, Yanqiang Zhou ${ }^{1,2}$, Zhian Sun ${ }^{1,2}$, Xiaoxiao Wang ${ }^{1,2}$ and Shanwen Zhao ${ }^{1,2}$
}

\begin{abstract}
A novel polystyrene sulfonate sodium (PSS) magnetic material was prepared by surface-initiated atom transfer radical polymerization (SI-ATRP). The starting materials were brominated magnetic material as the carrier and macroinitiator, sodium styrene sulfonate (NaSS) as the monomer, and cuprous bromide/2,2'-dipyridyl as the catalyst system. The PSS material was characterized by Fourier transform infrared spectroscopy (FT-IR), elemental analysis, transmission electron microscope (TEM), thermogravimetric analysis (TGA), scanning electron microscopy (SEM), and a vibrating sample magnetometer (VSM). The adsorption properties of the material were then investigated on sulfa antibiotics. The kinetic and thermodynamic parameters were determined in adsorption of sulfamethazine (the smallest molecularweight sulfonamide). The adsorption amount of sulfamerazine free acid (SMR) was found to increase with the initial concentration and temperature of SMR in solution. The adsorption effect was maximized at an initial concentration of $0.6 \mathrm{mmol} / \mathrm{L}$. The static saturation adsorption capacity of the material was $33.53 \mathrm{mg} / \mathrm{g}$, Langmuir and Freundlich equations exhibited good fit. The thermodynamic equilibrium equation is calculated as $\Delta G<0, \Delta H=38.29 \mathrm{~kJ} / \mathrm{mol}, \Delta S>0$, which proves that the adsorption process is a process of spontaneous, endothermic and entropy increase. Kinetic studies show that the quasi-second-order kinetic equation can better fit the kinetic experimental results, which is consistent with the quasi-second-order kinetic model. The experimental results of kinetic studies were well fitted to a quasi-second-order kinetic equation. High performance liquid chromatography (HPLC) of an actual milk sample treated by the PSS magnetic material confirmed the strong adsorption of SMR from milk.
\end{abstract}

Keywords: Polystyrene sulfonate sodium (PSS) magnetic material, Surface-initiated atom-transfer radical polymerization (SI-ATRP), Sulfonamide antibiotic, Adsorption performance, High performance liquid chromatography (HPLC)

\section{Introduction}

Sulfa drugs (SAs) are a class of synthetic anti-infective drugs with a wide antibacterial spectrum. They are also convenient to use and stable in nature. Owing to these advantages, SAs are widely used in aquaculture and

*Correspondence: gongbolin@163.com

${ }^{2}$ No. 204 Wenchang North Street, Xixia District, Yinchuan, People's

Republic of China

Full list of author information is available at the end of the article animal breeding [1-4]. However, bacteria easily become resistant to sulfa drugs, and sulfa drug residues can accumulate in animals after long-term use. Therefore, the United Nations Codex Alimentarius Commission (CAC) and many national regulations have limited the total amount of SAs in animal feed to $0.11 \mathrm{mg} / \mathrm{kg}[5,6]$. At present, sulfa drugs in China are mainly treated by simple physicochemical methods $[7,8]$, SBR (sequencing batch

(c) The Author(s) 2020. This article is licensed under a Creative Commons Attribution 4.0 International License, which permits use, sharing, adaptation, distribution and reproduction in any medium or format, as long as you give appropriate credit to the original author(s) and the source, provide a link to the Creative Commons licence, and indicate if changes were made. The images or other third party material in this article are included in the article's Creative Commons licence, unless indicated otherwise in a credit line to the material. If material is not included in the article's Creative Commons licence and your intended use is not permitted by statutory regulation or exceeds the permitted use, you will need to obtain permission directly from the copyright holder. To view a copy of this licence, visit http://creativeco mmons.org/licenses/by/4.0/. The Creative Commons Public Domain Dedication waiver (http://creativecommons.org/publicdomain/ zero/1.0/) applies to the data made available in this article, unless otherwise stated in a credit line to the data. 
activated sludge leads to normal flora imbalance in the body [9]), and adsorption methods [10, 11].

Surface-initiated atom-transfer radical polymerization (SI-ATRP) is a new actively controlled polymerization technology that enables "active" polymerization. Because it controls the graft chain length [12-14], SI-ATRP grafting is a popular surface graft-modification technique for various materials. Using SI-ATRP technology, Niu et al. [15] obtained an aminated resin with higher adsorption capacity for $\mathrm{Cu}(\mathrm{II}), \mathrm{Pb}(\mathrm{II}), \mathrm{Cr}(\mathrm{VI})$, and $\mathrm{As}(\mathrm{V})$ than traditional resins. By the same technology, Chen et al. [16] prepared a chelate resin with a 4-vinylpyridine ring as the functional group. This resin readily adsorbs $\mathrm{Cr}(\mathrm{VI})$, $\mathrm{Pb}(\mathrm{II})$, and $\mathrm{Cr}(\mathrm{III})$.

The unique magnetic properties of $\mathrm{Fe}_{3} \mathrm{O}_{4}$ magnetic nanomaterials have been widely exploited in magnetic fluids, data storage, and pollutant treatments $[17,18]$. Jin et al. [19] prepared monodispersed carboxylated $\mathrm{Fe}_{3} \mathrm{O}_{4}$ magnetic nanoparticles, and Cheng et al. [20] studied the adsorption performance of amino-functionalized mesoporous magnetic nanoparticles on $\mathrm{Cu}(\mathrm{II})$ in water, but not in actual samples. Therefore, the performance of their nanoparticles in real applications is unknown. To fill these gaps, we prepared magnetic materials by grafting modified $\mathrm{Fe}_{3} \mathrm{O}_{4}$ magnetic nanoparticles onto sodium styrene sulfonate, and testing their ability to adsorb antibiotics from food. To this end, we detected the adsorbed and remnant sulfa antibiotics in a food source (milk) treated by the magnetic material, which has not been reported in the prior literature.

In this study, the carrier/initiator was a brominated magnetic material, the monomer was sodium styrene sulfonate (NaSS), and the catalyst was cuprous bromide/2,2'-bipyridyl. A novel sodium polystyrene sulfonate magnetic material was prepared by the SI-ATRP technique. Adsorption and removal experiments of the sulfa antibiotics were performed under various conditions of the magnetic material, yielding informative results.

\section{Materials and methods Apparatus}

Experiments were carried out in the following instruments: an LC-20AT high performance liquid chromatograph (Shimadzu Corporation, Japan), a JEM-2100 transmission electron microscope (JEM, Japan), a JJ-1 precision factory electric mixer (Shanghai Specimen Model Factory), a collecting thermostatic heating magnetic stirrer (Zhengzhou Changcheng Branch Industry and Trade Co., Ltd.), a KQ-3200E ultrasonic cleaner (Kunshan Ultrasonic Instrument Co., Ltd.), a BS-224S electronic balance (Sedolis Scientific Instrument Co., Ltd.), an SHZ-C type water bath constant-temperature oscillator (Shanghai Pudong Physical Optics Instrument Factory), a TU-1810 UV-visible spectrophotometer, (Beijing Pu Analysis General Instrument Co., Ltd.), a TGL-20 M high-speed desktop centrifuge (Changsha Xiangyi Centrifuge Co., Ltd.) and a Fourier transform infrared spectrometer (Shimadzu, Japan). The absorbance was measured by the TU-1810 UV-Vis spectrophotometer purchased from Beijing Pu Analysis General Instrument Co., Ltd. The supernatant after adsorption by the material was photometrically determined to determine the absorption wavelength of the sulfonamides. Then, spectral scanning was performed, and different absorbances were measured and processed by UVWin 5 software to complete the experiment. The actual sample was analyzed by LC-20AT high performance liquid chromatography (Shimadzu Corporation, Japan). The instrument was equipped with DGU-20A3 degasser, 2 LC-20AT solvent transfer pumps (divided into $\mathrm{A}$ and $\mathrm{B}$ pumps), and $7725 \mathrm{i}$ manual feed. Sampler, CTO-20A column oven, SPD-20A UV-Vis detector and CBM-20A system controller. Diamonsil C18 column $(150 \mathrm{~mm} \times 4.6 \mathrm{~mm}, 5 \mu \mathrm{m})$, mobile phase acetonitrile-water $(25: 75, \mathrm{v} / \mathrm{v})$ and filtered through a $0.45 \mu \mathrm{m}$ filter with a flow rate of $0.8 \mathrm{~mL} / \mathrm{min}$ and a detection wavelength of $270 \mathrm{~nm}$ and set the injection volume of $20 \mu \mathrm{L}$.

\section{Reagents and materials}

Sodium styrene sulfonate (NaSS), sulfamerazine free acid (SMR), sulfadimethoxine (SDM), sulfafurazole (SIZ), sulfadimidine (SM2), N,N-dimethylformamide (DMF), 3-aminopropyltriethoxysilane (MSDS), $\alpha$-bromoisobutyryl bromide,hydroxylamine hydrochloride, oleic acid, tetraethyl orthosilicate (TEOS), cuprous bromide $(\mathrm{CuBr})$ and 2,2'-bipyridine (Bpy) were purchased from Aladdin Reagent Co., Ltd. (Shanghai, China). Ferric chloride hexahydrate $\left(\mathrm{FeCl}_{3} \cdot 6 \mathrm{H}_{2} \mathrm{O}\right)$, ethylenediaminetetraacetic acid (EDTA), aqueous ammonia $\left(\mathrm{NH}_{3} \cdot \mathrm{H}_{2} \mathrm{O}\right)$, hydrochloric acid $(\mathrm{HCl})$, acetonitrile, $\mathrm{m}$ ethylbenzene,sodium hydroxide $(\mathrm{NaOH})$, absolute ethyl alcohol,tetrahydrofuran, and triethylamine were purchased from Damao Chemical Reagent Factory (Tianjin, China).

\section{Preparation of magnetic $\mathrm{Fe}_{3} \mathrm{O}_{4} / \mathrm{SiO}_{2}$ nanocomposite particles}

$\mathrm{FeCl}_{3} \cdot 6 \mathrm{H}_{2} \mathrm{O}(60 \mathrm{~mL}, 0.05 \mathrm{~mol} / \mathrm{L})$ and ethanol-water (1:1 $\mathrm{v} / \mathrm{v})$ were placed in a round-bottomed flask and heated to $50{ }^{\circ} \mathrm{C}$ with magnetic stirring. At the start of stirring, $0.0511 \mathrm{~g}$ hydroxylamine hydrochloride was quickly added to the mixture. After 5 min of stirring, the $\mathrm{pH}$ was adjusted to $>9.0$ by adding $25 \%$ ammonium hydroxide. Next, $1 \mathrm{~mL}$ oleic acid was slowly (dropwise) added to the solution while warming to $70{ }^{\circ} \mathrm{C}$ for $10 \mathrm{~min}$. After stirring 
for a further $30 \mathrm{~min}$ at $70{ }^{\circ} \mathrm{C}$, the solution was allowed to cool to room temperature. The solids were then separated by a solid magnetic field. The resulting black precipitate was washed several times with absolute ethanol and vacuum-dried at $60^{\circ} \mathrm{C}$.

Weighed $\mathrm{Fe}_{3} \mathrm{O}_{4}$ particles $(1.00 \mathrm{~g})$ were ultrasonically dispersed in $100 \mathrm{~mL}$ ethanol-water $(4: 1 \mathrm{v} / \mathrm{v})$ for $10 \mathrm{~min}$. The dispersed solution was transferred to a $250-\mathrm{mL}$ three-necked bottle. After adding $2 \mathrm{~mL} \mathrm{25 \%}$ ammonium hydroxide and (slowly) $1 \mathrm{~mL}$ TEOS, the mixture was mechanically stirred until uniform, and the reaction was sealed for $24 \mathrm{~h}$. After completion of the reaction, the solution was repeatedly washed with distilled water under the magnetic-field separation conditions until it became neutral and no longer cloudy.

\section{Synthesis of $\mathrm{Fe}_{3} \mathrm{O}_{4} / \mathrm{SiO}_{2}$ grafted PSS composites}

Dried $\mathrm{Fe}_{3} \mathrm{O}_{4} / \mathrm{SiO}_{2}(1.00 \mathrm{~g})$ solid particles were weighed into a $100 \mathrm{~mL}$ three-necked flask. After adding $20 \mathrm{~mL}$ of absolute ethanol, the particles were ultrasonically dispersed for $15 \mathrm{~min}$. When the dispersion was complete, $3 \mathrm{~mL}$ of MSDS was added and the reaction was heated in a $90{ }^{\circ} \mathrm{C}$ oil bath for $24 \mathrm{~h}$ After completion of the reaction, the mixture was washed successively with toluene, secondary water and absolute ethanol until neutral, and vacuum-dried at $60^{\circ} \mathrm{C}$.

The aminosilylated $\mathrm{Fe}_{3} \mathrm{O}_{4} / \mathrm{SiO}_{2}(0.5 \mathrm{~g})$ was dispersed in $30 \mathrm{~mL}$ of tetrahydrofuran, and the reaction was stirred for $30 \mathrm{~min}$ in an ice bath. Triethylamine $(1.25 \mathrm{~mL})$ was then added dropwise, and the mixture was stirred at room temperature for $10 \mathrm{~min}$. After dropwise of $1 \mathrm{~mL}$ $\alpha$-bromoisobutyryl bromide, the reaction was left at room temperature for $20 \mathrm{~h}$ to complete the reaction. The product was washed twice with tetrahydrofuran, distilled water and acetone, and vacuum-dried at $60{ }^{\circ} \mathrm{C}$.

Initiator-modified $\mathrm{Fe}_{3} \mathrm{O}_{4} / \mathrm{SiO}_{2}(0.3 \mathrm{~g})$ was weighed into a $50 \mathrm{~mL}$ round-bottomed flask. After adding $0.0743 \mathrm{~g}$ Bpy, $0.0213 \mathrm{~g} \mathrm{CuBr}$, and $0.995 \mathrm{~g}$ sodium styrenesulfonate in $40 \mathrm{mLNN}$-dimethylformamide-water solution, the $\mathrm{Fe}_{3} \mathrm{O}_{4} / \mathrm{SiO}_{2}$ particles were ultrasonically dispersed for $15 \mathrm{~min}$. Nitrogen was then deaerated for $30 \mathrm{~min}$ at room temperature, and the reaction was sealed at $60{ }^{\circ} \mathrm{C}$ for $20 \mathrm{~h}$. After the reaction, the polymerization product was separated by a magnetic field, and the impurities in the precipitate were removed by sequential washing with saturated EDTA, distilled water and acetone (two washes in each cleaning agent). The product, polystyrene sulfonate sodium (PSS) magnetic material, was vacuum-dried at $60{ }^{\circ} \mathrm{C}$.

\section{Adsorption experiments}

Saturated adsorption capacity experiment: PSS magnetic material $(0.1 \mathrm{~g})$ was weighed into a $50 \mathrm{~mL}$ erlenmeyer flask. After adding $0.1 \mathrm{~mol}$ of $10 \mathrm{~mL}$ SMR to acetonitrile$\mathrm{NaOH}$ solution $(9: 1, \mathrm{v} / \mathrm{v})$ and shaking for $24 \mathrm{~h}$ in a water bath thermostat, the supernatant was extracted. The remaining concentration of SMR in the supernatant was determined, and the adsorbed amount $(\mathrm{mg} / \mathrm{g})$ was calculated as follows [21]:

$$
\mathrm{Q}=\frac{\left(C_{0}-C_{e}\right) V}{m}
$$

where $\mathrm{Q}$ is the amount of adsorption $(\mathrm{mg} / \mathrm{g}), \mathrm{C}_{0}$ and $\mathrm{C}_{\mathrm{e}}$ are the initial and adsorption equilibrium concentrations of SMR, respectively $(\mathrm{mmol} / \mathrm{L}), V$ is the solution volume $(\mathrm{mL})$, and $m$ is the mass $(\mathrm{g})$ of the PSS magnetic material.

Adsorption selectivity: To determine the adsorption selectivity of SMR, we prepared additional target molecules SDM, SM2, and SIZ, which are similar to SMR. Into solutions of $0.6 \mathrm{mmol} / \mathrm{L}$ acetonitrile $(10 \mathrm{~mL})$ and $0.1 \mathrm{~mol} / \mathrm{L} \mathrm{NaOH}(9: 1 \mathrm{v} / \mathrm{v})$ was weighed $0.1 \mathrm{~g}$ of magnetic material. The mixtures were oscillated in a water bath at constant temperature. After static adsorption for $24 \mathrm{~h}$, the absorbances of the supernatants were measured in a UV-visible spectrophotometer, and the adsorption amounts of the magnetic materials were calculated by Eq. (1).

Adsorption kinetics: The adsorption kinetics were measured under the condition of $\mathrm{pH}>7$. Magnetic material was added to the same concentration of SMR solution. The mixture was continually oscillated in a constant-temperature oscillator and sampled regularly. The adsorption amounts were determined from the absorbances measured at each sampling time, and an adsorption amount-time curve was plotted to determine the adsorption rate. The experimental results were analyzed by different kinetic models and the kinetic reaction order was determined.

Adsorption thermodynamics: The adsorption thermodynamics were measured under the condition of $\mathrm{pH}>7$, a constant amount of the magnetic materials was added to different initial concentrations of SMR solution. The solutions were continually oscillated in a constant-temperature oscillator. The adsorption was balanced and sampled. The adsorption isotherm was obtained by plotting the equilibrium concentrations and the corresponding equilibrium adsorption amounts as the abscissa and ordinate, respectively. The adsorption amounts were investigated at different temperatures, and the relevant thermodynamic parameters were calculated from the results.

\section{Adsorption properties under different $\mathrm{pH}$}

$0.1 \mathrm{~g}$ of sodium polystyrene sulfonate magnetic material was placed in an aqueous solution at $25{ }^{\circ} \mathrm{C}$, and the $\mathrm{pH}$ values were 4.0, 5.0, 6.0, 7.0, 8.0, 9.0, and 10.0, 
respectively. The initial concentration of the SMR solution was $0.6 \mathrm{mmol} / \mathrm{L}$. Adsorption was carried out for $7.5 \mathrm{~h}$ under magnetic stirring. And calculate the adsorption amount of SMR.

\section{Sample processing}

Milk samples $(5 \mathrm{~mL})$ were accurately transferred into a $50 \mathrm{~mL}$ centrifuge tube. After adding a certain amount of the sulfa drug standard solution, $1 \mathrm{~mL}$ hydrochloric acid solution $(1 \mathrm{~mol} / \mathrm{L})$ and $15 \mathrm{~mL}$ acetonitrile, the mixture was ultrasonicated for $20 \mathrm{~min}$, then centrifuged at $4000 \mathrm{rpm}$ for $10 \mathrm{~min}$. The supernatant was collected through a filtration membrane, spin-dried, then reconstituted in $5 \mathrm{~mL}$ of acetonitrile. The vials were placed in the refrigerator for later use.

\section{Results and discussion}

\section{Preparation of magnetic PSS}

Magnetic $\mathrm{Fe}_{3} \mathrm{O}_{4}$ nanoparticles were prepared by the coprecipitation method. Their surfaces were then coated with $\mathrm{SiO}_{2}$ to form a core-shell structure. The coated nanoparticles were sequentially reacted with 3-aminopropyltriethoxysilane and $\alpha$-bromoisobutyryl bromide to obtain the SI-ATRP initiator. Next, the polymerization monomer NaSS was grafted onto the initiator surface by SIATRP polymerization in an acetonitrile- $\mathrm{NaOH}$ solvent medium. The reaction was catalyzed by $\mathrm{CuBr}$ and Bpy was the complexing agent. The preparation process of the magnetic PSS adsorption material is shown in Fig. 1.

\section{Instrumental characterization}

Figure 2 displays the thermogravimetric plots of $\mathrm{Fe}_{3} \mathrm{O}_{4} /$ $\mathrm{SiO}_{2} / \mathrm{Br}$ and PSS. The $\mathrm{Fe}_{3} \mathrm{O}_{4} / \mathrm{SiO}_{2} / \mathrm{Br}$ (a) was highly stable, losing only $10 \%$ of its weight between room temperature

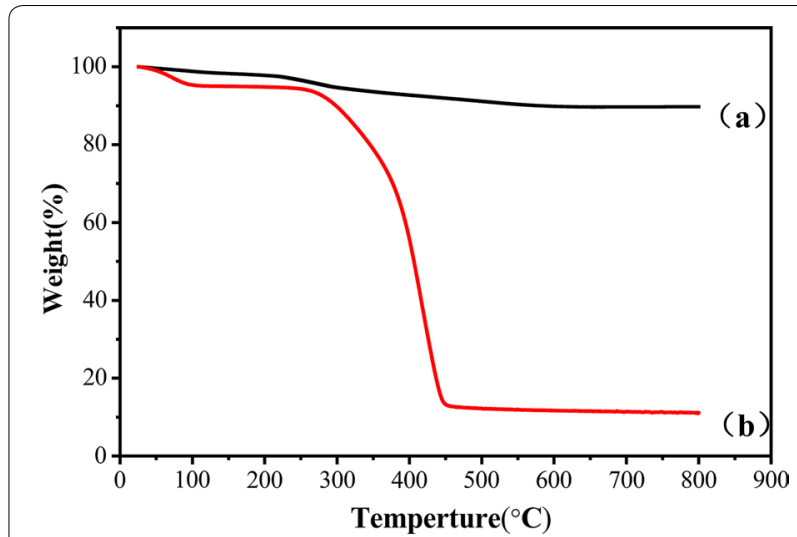

Fig. 2 TGA curves of the $\mathrm{Fe}_{3} \mathrm{O}_{4} / \mathrm{SiO}_{2} / \mathrm{Br}(\mathbf{a})$ and PSS (b) magnetic microspheres

and $800{ }^{\circ} \mathrm{C}$. Below $150{ }^{\circ} \mathrm{C}$, the weight loss of $\mathrm{Fe}_{3} \mathrm{O}_{4} / \mathrm{SiO}_{2} /$ $\mathrm{Br}$ and PSS is mainly attributable to evaporation of the residual ethanol layer. As the temperature was raised from 300 to $500{ }^{\circ} \mathrm{C}$, the weight loss from PSS was large and rapid. At $500{ }^{\circ} \mathrm{C}$, the PSS had lost $80.3 \%$ of its initial weight, mainly by decomposition of NaSS.

The SI-ATRP initiators before and after the NaSS grafting were characterized by elemental analysis. The $C$ and $\mathrm{H}, \mathrm{S}$ contents were higher in the final SI-ATRP-based adsorbent than in the SI-ATRP initiator (Table 1). The graft amount was calculated as follows [22]:

$$
\text { Graft amount }=M_{n} W_{\mathrm{S}} / N_{\mathrm{S}} M_{\mathrm{S}}
$$

where $\mathrm{W}_{\mathrm{S}}$ is the percentage of the $\mathrm{S}$ element per unit volume of the magnetic material surface; $\mathrm{N}_{S}$ is the number of $S$ elements per unit volume of the monomer; $M_{S}$ is the relative molecular mass of the $S$ element; $M_{n}$ is the molar

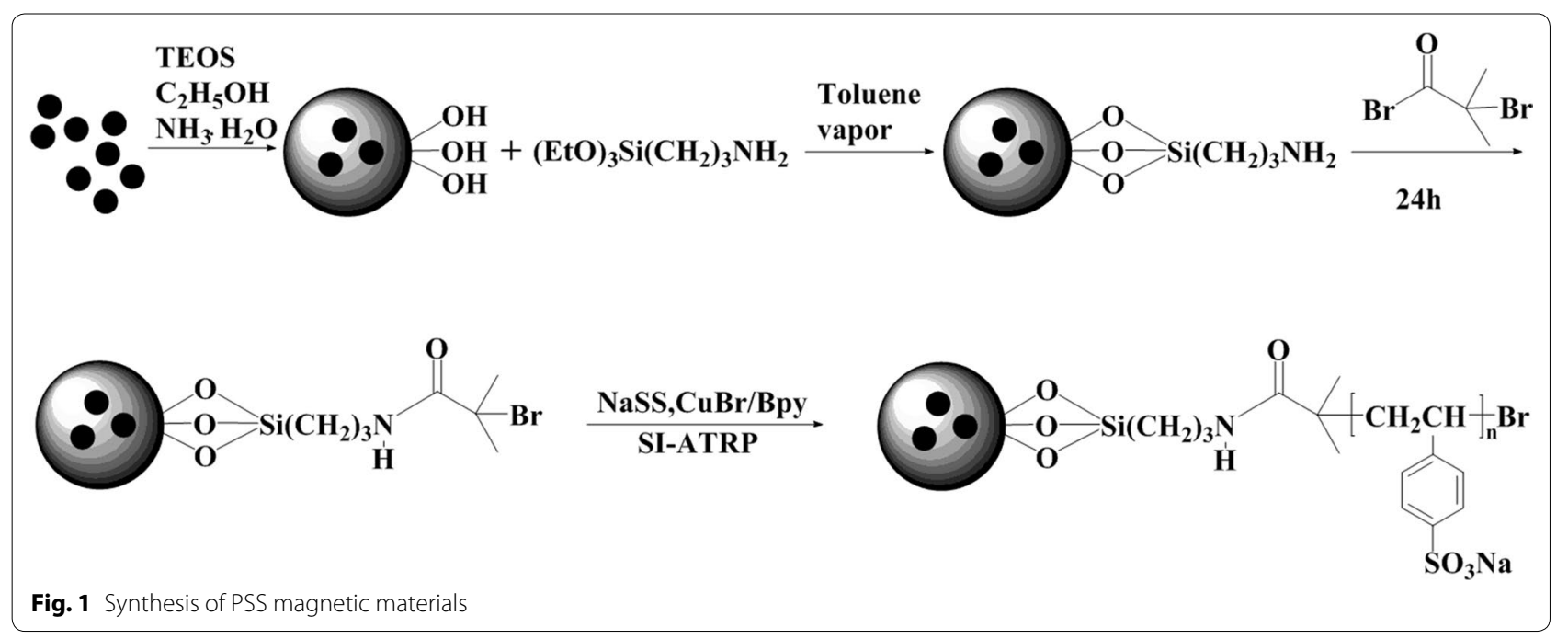


Table 1 Elemental analysis results

\begin{tabular}{lllll}
\hline Sample & C & H & N & S \\
\hline $\mathrm{Fe}_{3} \mathrm{O}_{4} / \mathrm{SiO}_{2} / \mathrm{NH}_{2} / \mathrm{Br}$ & 83.51 & 5.705 & 1.013 & - \\
$\mathrm{PSS}$ & 84.90 & 5.975 & 3.272 & 1.327 \\
\hline
\end{tabular}

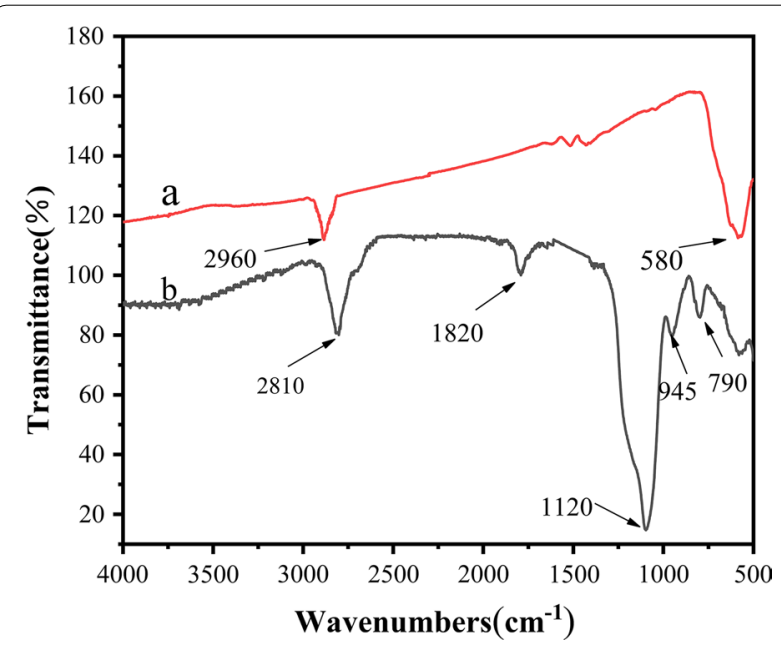

Fig. 3 Infrared spectra of $\mathrm{Fe}_{3} \mathrm{O}_{4}(\mathbf{a})$ and PSS (b)

mass of the monomer. The graft amount calculated by Eq. (2) was $27.99 \mu \mathrm{mol} / \mathrm{m}^{2}$, indicating that the $\mathrm{NaSS}$ had been successfully grafted onto the surface of the SI-ATRP initiator.

Figure 3 shows the infrared spectra of the $\mathrm{Fe}_{3} \mathrm{O}_{4}$ and PSS materials. In the spectrum of oleic acid modified $\mathrm{Fe}_{3} \mathrm{O}_{4}$, the peaks around $2960 / \mathrm{cm}$ and $580 / \mathrm{cm}$ are the characteristic absorption peaks of $-\mathrm{CH}_{3}$ in oleic acid and the stretching vibration of $\mathrm{Fe}-\mathrm{O}$ bonds, respectively. In the PSS spectrum, the strong absorption peak at 1120/ $\mathrm{cm}$ is attributable to asymmetric stretching vibrations of $\mathrm{Si}-\mathrm{O}-\mathrm{Si}$. Peaks attributable to $\mathrm{Si}-\mathrm{O}$ vibrations $(790 / \mathrm{cm})$ and $\mathrm{Si}-\mathrm{O}-\mathrm{H}$ vibrations $(945 / \mathrm{cm})$ are also clarified. These peaks indicate that $\mathrm{SiO}_{2}$ was successfully coated on the $\mathrm{Fe}_{3} \mathrm{O}_{4}$ surface. The in-plane skeleton vibration of the benzene ring at $1450 / \mathrm{cm}$ and the characteristic peak of the $\mathrm{Fe}-\mathrm{O}$ bond at $580 / \mathrm{cm}$ are also less affected by the benzene ring. The absorption peak at $2810 / \mathrm{cm}$ is assigned to stretching vibrations of saturated $\mathrm{C}-\mathrm{H}$. The characteristic $\mathrm{C}-\mathrm{C}$ peak is absent. The stretching vibration peak of $\mathrm{C}=\mathrm{O}$ at $1820 / \mathrm{cm}$ indicates that the successful preparation of PSS magnetic material.

Scanning electron microscopy was used to characterize the surface morphology and structure of PSS materials before and after adsorption. The results are shown in Fig. 4, in which Fig. 4a is a magnetic material before adsorption, and Fig. $4 \mathrm{~b}$ is a saturated magnetic material after adsorption of SMR. It can be seen in the figure that the surface morphology of the resin before and after adsorption has undergone a great change. Before the adsorption, the material morphology is obvious and pores with different sizes are formed, and the surface is uneven. The surface of the resin became smooth after adsorption and the pore size and size also changed. It shows that after the adsorption of SMR, the surface of the material changes significantly, so it shows that the magnetic material has good adsorption to SMR. At the same time, the synthesized materials were characterized by transmission electron microscope (TEM) [23]. The results are shown in Fig. 4c, d. It can be clearly seen in the figure that the synthesized material has a core-shell structure, which proves that the magnetic material is successfully prepared.

The oleic acid-modified $\mathrm{Fe}_{3} \mathrm{O}_{4}$ nanoparticles, $\mathrm{Fe}_{3} \mathrm{O}_{4} /$ $\mathrm{SiO}_{2}, \mathrm{Fe}_{3} \mathrm{O}_{4} / \mathrm{SiO}_{2} / \mathrm{NH}_{2}$ and PSS were analyzed by VSM at room temperature. The magnetization curves of the four materials are presented in Fig. 5. The inset is a photograph of the magnetic separation under an external magnetic field. The saturation magnetization of the $\mathrm{Fe}_{3} \mathrm{O}_{4}$ nanoparticles was $60.67 \mathrm{emu} / \mathrm{g}$, close to the reported magnetic susceptibility of this material. The measured value is smaller than the saturation magnetic susceptibility theoretically obtained from the standard material, possibly because of particle surface effects. After each step, the saturation magnetization of the PSS nanoparticles was reduced to $10.14 \mathrm{emu} / \mathrm{g}$ and higher than the literature report $[24,25]$, because the magnetic responsiveness of the PSS was suppressed by the non-magnetic layer coated on its surface. Before the magnetic field was applied, the PSS were uniformly dispersed in the acetonitrile solution (Fig. 5e), but under the external magnetic field, the tan particles were rapidly attracted to the wall of the bottle. On the side, the solution became transparent (Fig. 5e, left), confirming the high magnetic responsiveness of the PSS and its suitability as a magnetic separation carrier.

\section{Adsorption performance of PSS magnetic materials}

Effect of initial SMR concentration on adsorption capacity: Concentration is an important factor affecting the adsorption process. Figure 6 plots the SMR adsorption capacity of the PSS magnetic material versus the initial SMR concentration. The amount of adsorbed SMR gradually increased with initial concentration, likely because the probability of contact between SMR and adsorbent increases when the absorbent is dense in the solution. When the initial concentration exceeded $0.6 \mathrm{mmol} / \mathrm{L}$, the adsorption amount saturated and was not further changed by increasing the initial SMR concentration. The adsorption amount was $33.53 \mathrm{mg} / \mathrm{g}$, higher than 

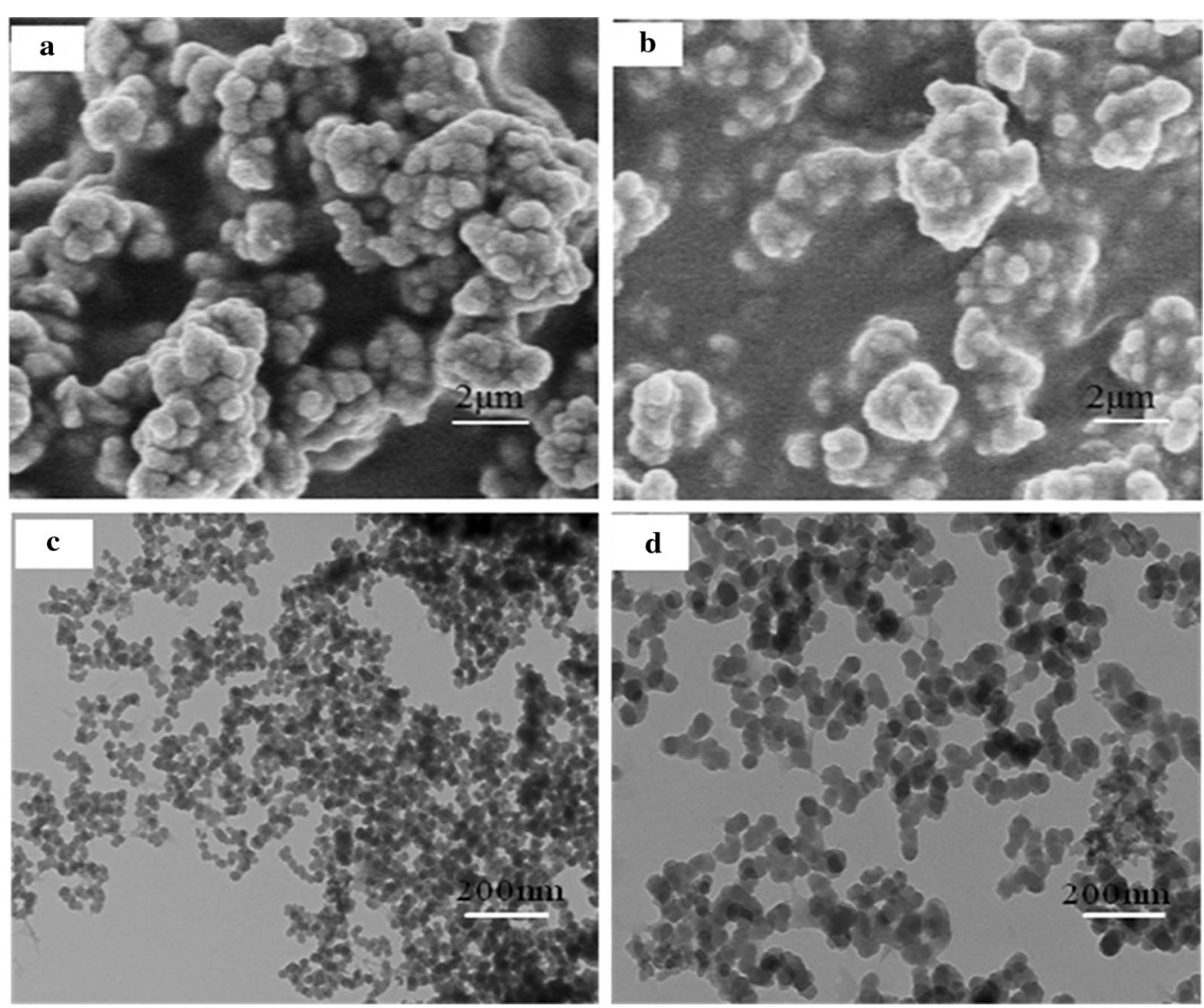

Fig. 4 SEM images of the PSS magnetic material before (a) and after (b) SMR adsorption and TEM of PSS material

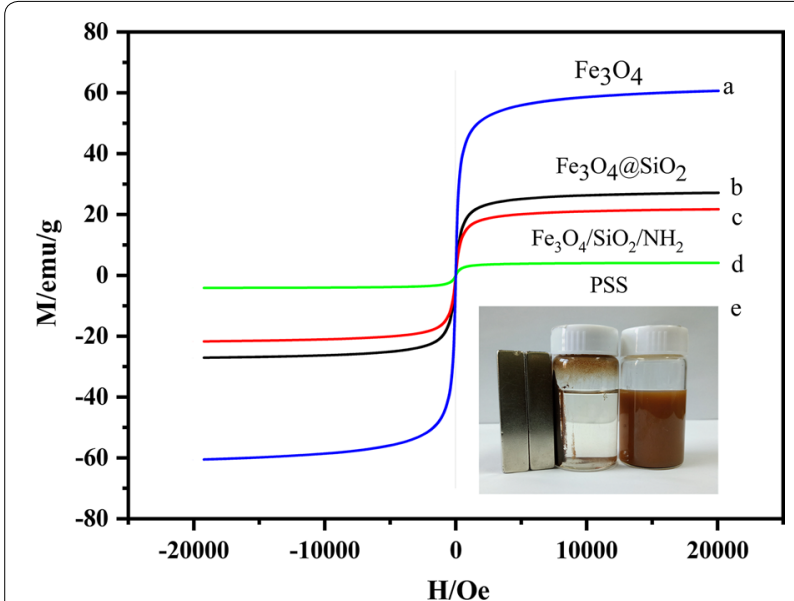

Fig. 5 Magnetization characteristics (hysteresis curves) of a $\mathrm{Fe}_{3} \mathrm{O}_{4}$ nanomaterials, $\mathbf{b ~ F e} \mathrm{O}_{4} / \mathrm{SiO}_{2}, \mathbf{c} \mathrm{Fe}_{3} \mathrm{O}_{4} / \mathrm{SiO}_{2} / \mathrm{NH}_{2}$, d PSS. e Photograph of magnetic separation in PSS

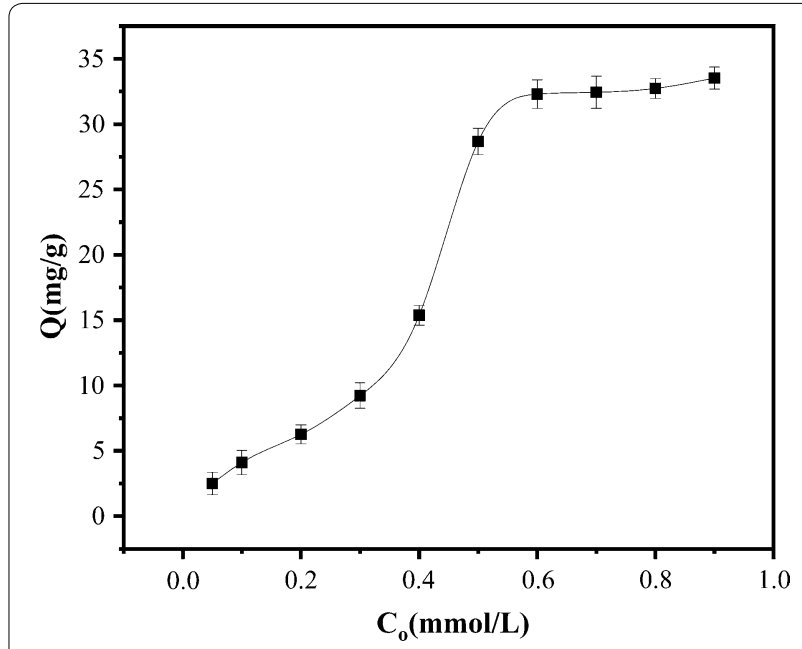

Fig. 6 Effect of initial SMR concentration on the adsorption capacity of PSS magnetic material 
<smiles>Cc1ccnc(NS(=O)(=O)c2ccc(N)cc2)n1</smiles><smiles>Cc1cc(C)nc(NS(=O)(=O)c2ccc(N)cc2)n1</smiles><smiles>COc1cc(NS(=O)(=O)c2ccccc2)nc(OC)n1</smiles>

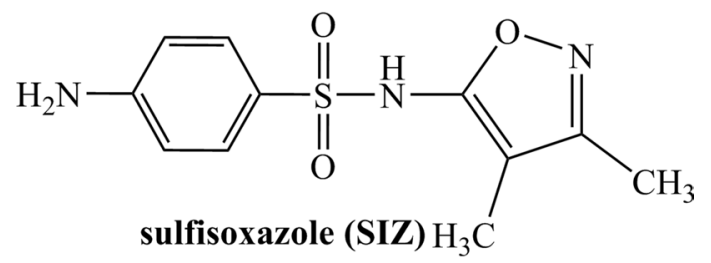

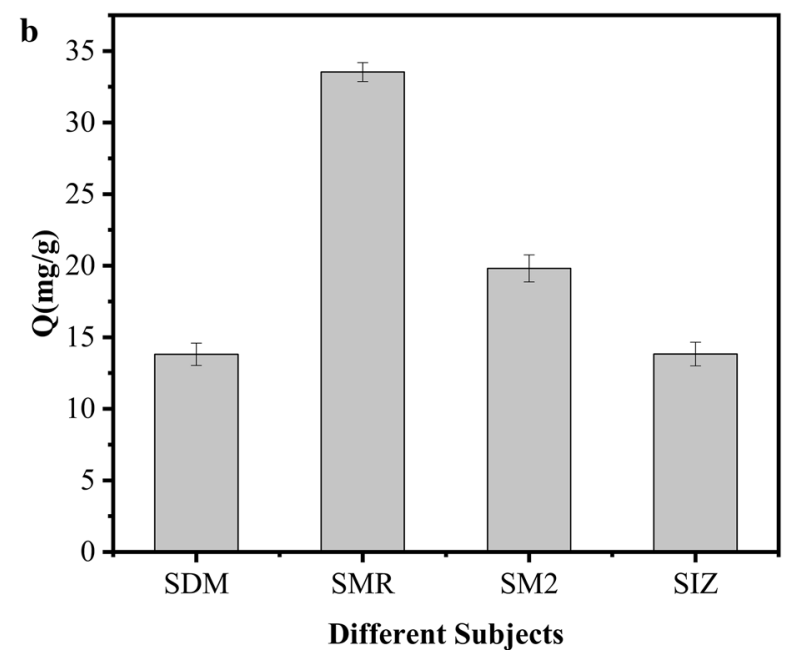

Fig. 7 a Structures of the four sulfonamides. b Effect of substrate on adsorption capacity

the reported value $[26,27]$. Therefore, $0.6 \mathrm{mmol} / \mathrm{L}$ was deemed the optimal initial SMR concentration.

Determination of selective adsorption: As shown in Fig. 7a, b, the SMR, SDM, SIZ and SM2 materials were similar in structure, but the adsorption capacity was much higher for SMR than for the other sulfonamides. We surmise that SMR is less sterically hindered than SM2, SDM, and SIZ, so is more easily adsorbed to the magnetic material [28].

Temporal changes in adsorption capacity: Fig. 8 plots the temporal changes in the amount of SMR adsorbed by the magnetic material. The initial SMR concentration was $0.6 \mathrm{mmol} / \mathrm{L}$. The SMR was rapidly adsorbed during the first $5.5 \mathrm{~h}$. After this time, the adsorption rate gradually decreased toward zero at adsorption equilibrium. The fast initial rate is attributable to the large number of adsorption active sites on the surface of the magnetic material. Over time, these sites gradually

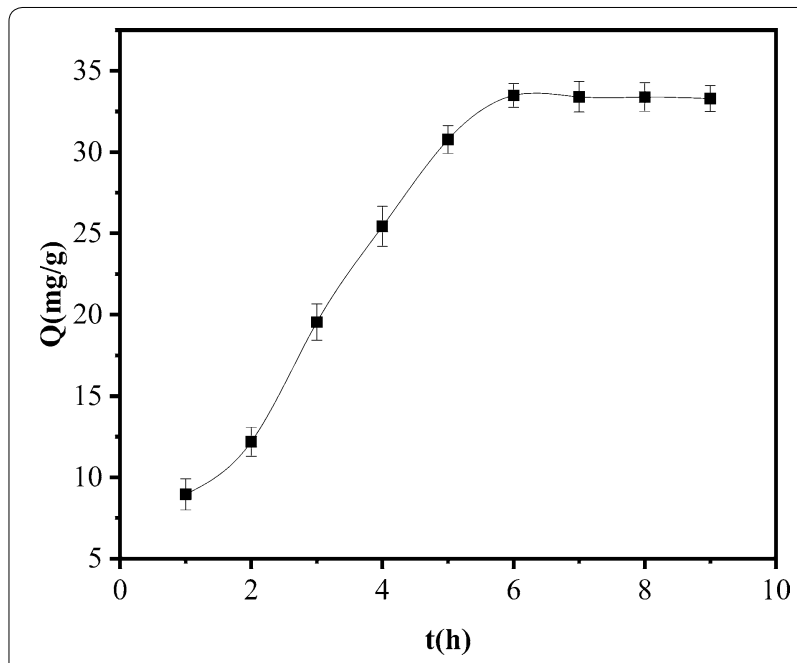

Fig. 8 Temporal dynamics of SMR amount adsorbed to PSS magnetic material 
become occupied by SMR molecules, so the adsorption rate slows until adsorption equilibrium is reached. The adsorption time in subsequent experiments was thus chosen as $7.5 \mathrm{~h}$.

Determination of number of reaction stages: Adsorption kinetics are commonly described by quasi-first-order and quasi-second-rate models. The quasi-first-order rate equation is also called the Lagergren first-order kinetic equation. The two models are usually linearized as [29].

$$
\begin{aligned}
& \ln \left(Q_{e}-Q_{t}\right)=\ln Q_{e}-\mathrm{k}_{1} t \\
& \mathrm{t} / Q_{\mathrm{t}}=\left(\mathrm{k}_{2} Q_{e}^{2}\right)^{-1}+\mathrm{t} / Q_{e}
\end{aligned}
$$

In these expressions, $Q_{t}$ is the adsorption amount $(\mathrm{mg} / \mathrm{g})$ at time $\mathrm{t}, Q_{e}$ is the equilibrium adsorption amount $(\mathrm{mg} / \mathrm{g})$ of the material, and $\mathrm{k}_{1}\left(\mathrm{~min}^{-1}\right)$ and $\mathrm{k}_{2}$ [g/ (mg.min)] are the primary and secondary rate parameters, respectively.

Fitting the experimental data in Fig. 8 using quasifirst-order and quasi-second-order reaction kinetic equations,the results of the fitting are shown in Table 2. The reaction order was determined by the correlation coefficient of the regression equation and the difference between the experimental and computed $Q_{e}$ values. The results show that the adsorption process of SMR by the PSS magnetic material was consistent with the secondorder kinetic model. The adsorption quantity $\left(\mathrm{Q}_{\mathrm{e}}\right.$, cal $)$ calculated by the second-order kinetic model is very close to the experimentally measured adsorption quantity $\left(Q_{e}\right.$, exp), and the correlation coefficient is good. In most cases, the Lagergren first-order kinetic equation can only be applied to the initial stage of the adsorption process rather than the entire stage; while the secondorder reaction kinetic model assumes that the rate-limiting step may be chemisorption and is suitable for many adsorption studies [30].

Effect of temperature on adsorption capacity of the PSS magnetic material: Temperature is another important factor affecting the adsorption process. To assess the temperature dependence of SMR adsorption to the PSS magnetic material, the SMR concentration was maintained constant at $0.6 \mathrm{mmol} / \mathrm{L}(0.01 \mathrm{~g}$ magnetic material in $10 \mathrm{~mL} \mathrm{SMR-methanol} \mathrm{solution),} \mathrm{and} \mathrm{the} \mathrm{SMR} \mathrm{con-}$ tent in the supernatant was determined after shaking for 7.5 h at $0{ }^{\circ} \mathrm{C}, 15^{\circ} \mathrm{C}, 25^{\circ} \mathrm{C}, 35^{\circ} \mathrm{C}$, or $45^{\circ} \mathrm{C}$ in a constanttemperature oscillator. As shown in Fig. 9, the adsorption amount increased with increasing temperature, indicating that the adsorption process was endothermic.

Effect of $\mathrm{pH}$ on Adsorption Properties of Magnetic Materials: Fig. 10 shows the effect of $\mathrm{pH}$ on the adsorption properties of magnetic materials. It can be seen from the figure that the change of $\mathrm{pH}$ has different adsorption effects on its adsorption performance.

Adsorption isotherm model: The adsorption isotherm relates the equilibrium adsorption amount to the equilibrium concentration at a certain temperature. The equilibrium adsorption amount $Q_{e}$ was calculated at various equilibrium concentrations $C_{e}$ measured in the static equilibrium adsorption experiment. In this experiment,

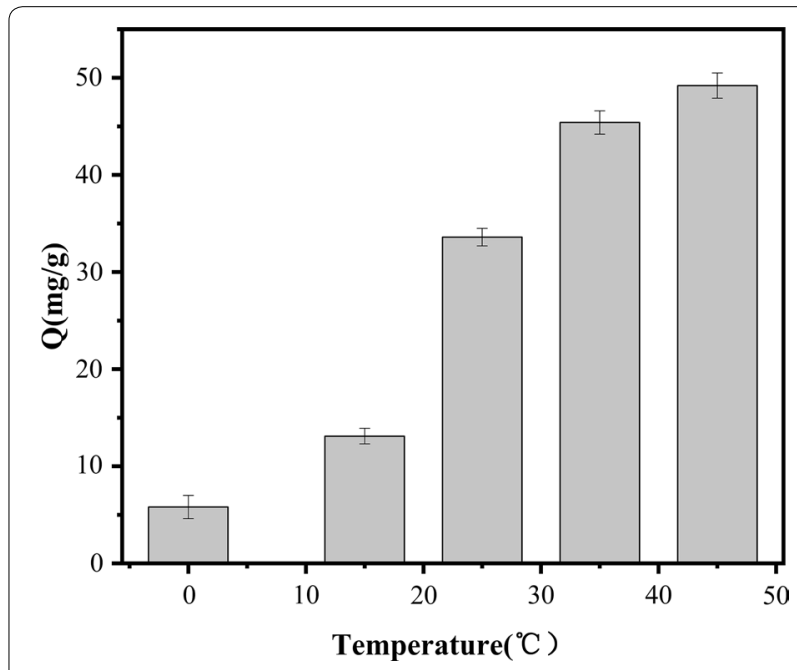

Fig. 9 Effect of temperature on adsorption capacity of PSS magnetic material

\begin{tabular}{|c|c|c|c|c|c|c|c|}
\hline Model & $\begin{array}{l}\text { Initial SMR } \\
\text { concentration } \\
\text { (mmol/L) }\end{array}$ & Equations & $K_{1}\left(\min ^{-1}\right)$ & $\mathrm{K}_{2}\left(\mathrm{~g} \mathrm{mg}^{-1} \mathrm{~min}^{-1}\right)$ & $R^{2}$ & $Q_{e^{\prime} \text { cal }}$ & $Q_{e, \exp }$ \\
\hline $\begin{array}{l}\text { Pseudo } \\
\text { first order } \\
\text { kinetic } \\
\text { model }\end{array}$ & 0.6 & $\ln \left(1-Q_{t} / Q_{e}\right)=-0.7013 t+0.7192$ & 0.7013 & - & 0.7844 & $32.51 \mathrm{mg} / \mathrm{g}$ & $33.53 \mathrm{mg} / \mathrm{g}$ \\
\hline $\begin{array}{l}\text { Pseudo sec- } \\
\text { ond order } \\
\text { kinetic } \\
\text { model }\end{array}$ & 0.6 & $\mathrm{t} / Q_{t}=0.0301 \mathrm{t}+10.0866$ & - & 0.00009 & 0.9998 & $33.22 \mathrm{mmol} / \mathrm{g}$ & $33.53 \mathrm{mmol} / \mathrm{g}$ \\
\hline
\end{tabular}

Table 2 The results of kinetics analysis 


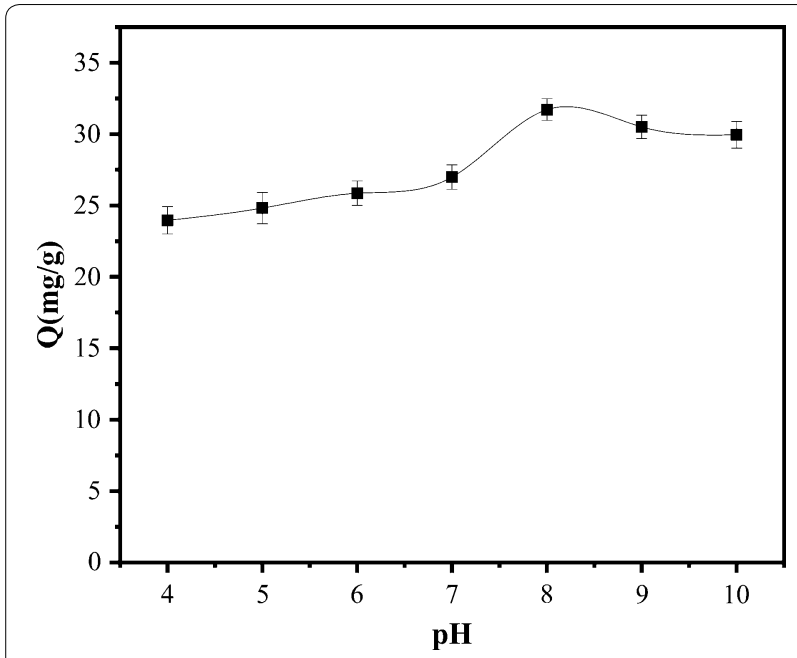

Fig. 10 Effect of pH on adsorption capacity

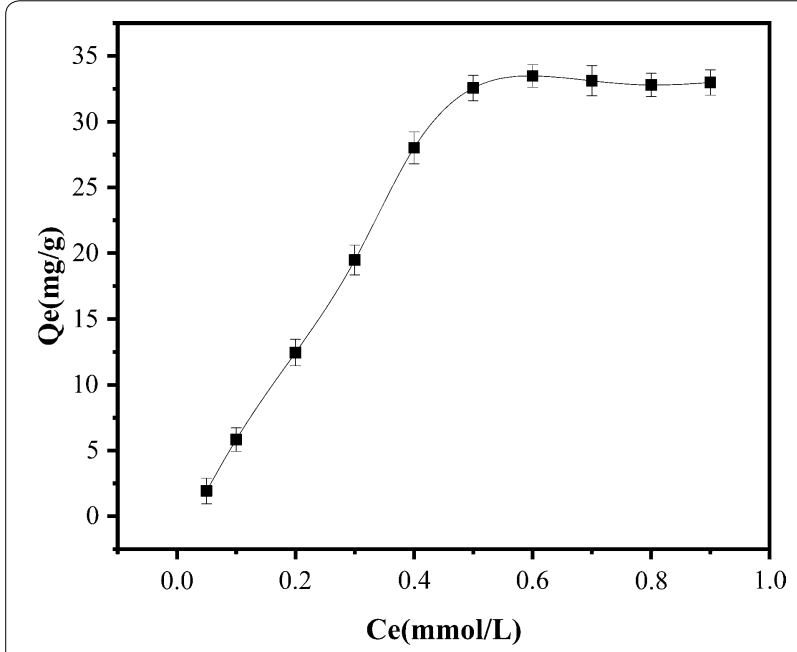

Fig. 11 Adsorption isotherm of SMR at $25^{\circ} \mathrm{C}$

Table 3 Fitting parameters of the Freundlich isotherm for SMR adsorption to PSS magnetic material

\begin{tabular}{lllll}
\hline $\mathbf{T}\left({ }^{\circ} \mathbf{C}\right)$ & Fitting equation & $\boldsymbol{K}_{\boldsymbol{F}}(\mathbf{m m o l} / \mathbf{g})$ & $\boldsymbol{n}$ & $\boldsymbol{R}^{\mathbf{2}}$ \\
\hline 25 & $\ln Q_{e}=0.2857 \ln C_{e}-1.8923$ & 0.1507 & 3.5002 & 0.9674 \\
\hline
\end{tabular}

the adsorption isotherm of the magnetic material was obtained at $25^{\circ} \mathrm{C}$, and is plotted in Fig. 11.

As evidenced in Fig. 11, the amount of adsorbed SMR at equilibrium increased with equilibrium concentration. The saturated adsorption capacity of the magnetic material at $25{ }^{\circ} \mathrm{C}$ was $33.53 \mathrm{mg} / \mathrm{g}$, higher than that of a molecularly imprinted polymer reported in the literature [31]. It appears that the magnetic material can have
Table 4 Fitting parameters of the Langmuir isotherm for SMR adsorption to PSS magnetic material

\begin{tabular}{lllll}
\hline $\mathbf{T}\left({ }^{\circ} \mathbf{C}\right)$ & Langmuir equation & $\boldsymbol{K}_{\mathbf{L}}(\mathbf{L} / \mathbf{m m o l})$ & $\boldsymbol{Q}_{\boldsymbol{m}}(\mathbf{m g} \mathbf{g})$ & $\boldsymbol{R}^{\mathbf{2}}$ \\
\hline 25 & $C_{e} / Q_{e}=0.0271 C_{e}+0.0018$ & 15.5032 & 36.84 & 0.9836 \\
\hline
\end{tabular}

Table 5 Thermodynamic parameters of adsorption

\begin{tabular}{llll}
\hline $\mathbf{T}(\mathrm{K})$ & $\boldsymbol{\Delta} \mathbf{G}(\mathbf{k J} / \mathbf{m o l})$ & $\boldsymbol{\Delta} \mathbf{H}(\mathbf{k J} / \mathbf{m o l})$ & $\boldsymbol{\Delta S}[\mathbf{J} /(\mathbf{m o l ~ K})]$ \\
\hline 288 & -2.394 & 38.29 & 141.26 \\
298 & -2.478 & & 136.81 \\
308 & -2.561 & & 132.63 \\
\hline
\end{tabular}

a higher adsorption capacity for the SMR. The above adsorption isotherm was then fitted by the Freundlich and Langmuir isotherm adsorption equations. The fitting parameters are shown in Tables 3 and 4, respectively. The correlation coefficients of both fits exceeded 0.95 , and $n$ in the Freundlich equation was greater than unity. It was concluded that both isotherm adsorption equations can adequately describe the adsorption process of SMR on magnetic materials.

Langmuir adsorption isotherm:

$$
C_{e} / Q_{e}=C_{e} / Q_{m}+\left(K_{L} Q_{m}\right)^{-1}
$$

Freundlich adsorption isotherm:

$$
\ln Q_{e}=n^{-1} C_{e}+\ln K_{F}
$$

In Eq. (5), $Q_{m}$ is the theoretical maximum adsorption amount $(\mathrm{mg} / \mathrm{g})$ of the material, and $K_{L}$ is the Langmuir adsorption equilibrium constant (L/mg). In Eq. (6), $K_{F}$ is the material adsorption capacity $(\mathrm{mg} / \mathrm{g})$, and $n$ denotes the affinity of the material for the adsorbate. The results of the Langmuir and Freundlich isotherm adsorption equations are shown in Tables 3 and 4.

Calculation of thermodynamic constants: To investigate the thermodynamics of the adsorption process, we computed the Gibbs free energy change $\Delta \mathrm{G}$, the adsorption enthalpy change $\Delta H$, and the entropy change $\Delta S$ [32]. The values of $\Delta \mathrm{G}, \Delta \mathrm{H}$, and $\Delta \mathrm{S}$ are shown in Table 5. Judging from the negative Gibbs free energy, the SMR spontaneously adhered to the magnetic material under isothermal conditions. Meanwhile, the positive enthalpy indicates that the adsorption was an endothermic process, and that raising the temperature will enhance the adsorption. Physical and chemical adsorptions occur in different $\Delta \mathrm{H}$ ranges: $2.1-20.9 \mathrm{~kJ} /$ $\mathrm{mol}$ and $20.9-418.4 \mathrm{~kJ} / \mathrm{mol}$, respectively [33]. The present results confirm that SMR adsorbed to the material 


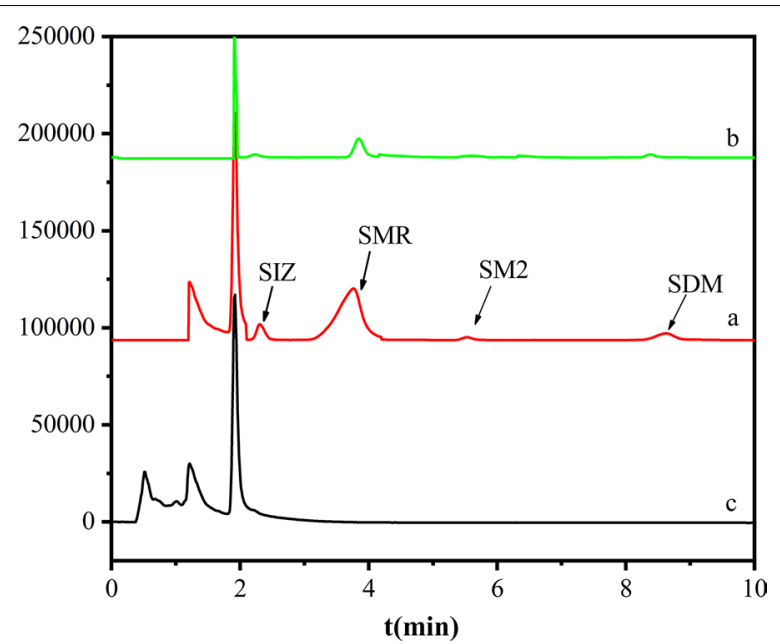

Fig. 12 Adsorption chromatograms of SMR in milk samples: a SMR before adsorption by magnetic material $\mathbf{b}$, after adsorption by magnetic material, and $\mathbf{c}$ blank sample

surface by a chemical process. Moreover, the entropy change $\Delta \mathrm{S}$ of the adsorption process was positive, indicating that SMR adsorption increased the degree of freedom of the liquid-solid interface.

\section{Testing in an actual food sample}

Finally, the milk sample treated with the PSS magnetic material was subjected to HPLC measurement, and as a result, as shown in Fig. 12c, no sulfonamide was detected. The adsorption chromatograms of SMR in the milk samples are shown in Fig. 12. No sulfonamide was detected in the blank sample (Fig. 12c). As the experimental samples, three kinds of sulfa antibiotics with concentrations of 10,50 and $100 \mu \mathrm{g} / \mathrm{mL}$ were added to the milk samples by spiked recovery. After treatment, HPLC was performed. As shown in Fig. 12a, the four antibiotics SIZ, SMR, SM2, and SDM were well separated along the chromatogram, and were adsorbed by $0.10 \mathrm{~g}$ of magnetic material. At adsorption equilibrium, the particles were separated by applying a magnetic field, and the supernatant was extracted and subjected to HPLC measurements (Fig. 12b). The magnetic material effectively adsorbed the SMR from milk. The removal rates of SIZ, SMR, SM2, and SDM were calculated as $83.36 \%, 94.36 \%, 63.36 \%$, and $58.41 \%$, respectively, confirming that the magnetic material can adsorb and remove sulfa antibiotics from real liquid food samples.

Three SMR standard samples with concentrations of 10,50 and $100 \mu \mathrm{g} / \mathrm{mL}$ were added by sample spike method. The experimental results are shown in Table 6 . Different loading amounts were added to prepare different recovery rates and relative standard deviations. The
Table 6 Recovery results of spiked SMR in milk $(n=3)$

\begin{tabular}{llll}
\hline Sample & $\begin{array}{l}\text { Scaling amount } \\
(\boldsymbol{\mu} \mathbf{g} / \mathbf{m L})\end{array}$ & Recovery (\%) & RSD (\%) \\
\hline SMR & 10 & 81.1 & 3.7 \\
& 50 & 102.7 & 3.1 \\
& 100 & 98.3 & 2.6 \\
\hline
\end{tabular}

recovery rate was 81.1 to $102.7 \%$, and the relative standard deviation (RSD \%) was 2.6 to $3.7 \%$. The detection limit was $8.01 \mu \mathrm{g} / \mathrm{L}$ with a three-fold signal-to-noise ratio $(\mathrm{S} / \mathrm{N})$. It is proved that the magnetic material has a good adsorption detection study on SMR in milk.

\section{Conclusions}

PSS magnetic material was prepared by the SI-ATRP technique. The adsorption properties, thermodynamics, and kinetic parameters of the material were investigated in the presence of sulfa antibiotics. SMR (the smallest molecular-weight sulfonamide) was selected for analysis. At $25{ }^{\circ} \mathrm{C}$ and an initial SMR concentration of $0.6 \mathrm{mmol} / \mathrm{L}$, the saturated SMR adsorption capacity of the magnetic material was $33.53 \mathrm{mg} / \mathrm{g}$. The adsorption properties of the sulfa antibiotics on the material were well fitted by the Langmuir and Freundlich equations. According to the thermodynamic parameters, The thermodynamic parameters indicate that the adsorption process is a spontaneous endothermic process, and the elevated temperature is favorable for adsorption. Kinetic studies show that the adsorption process conforms to the quasi-second-order kinetic equation.

\section{Abbreviations}

CAC: Codex Alimentarius Commission; NaSS: sodium styrene sulfonate; PSS: polystyrene sulfonate sodium.

\section{Acknowledgements}

Authors would like to thank the National Natural Science Foundation of China for supporting this study.

\section{Authors' contributions}

HCL presented experimental research and edited manuscripts, YQZ and ZAS coordinated research and review manuscripts, and XXW and SWZ coordinated research and review manuscripts. All authors read the manuscript and participated in presenting the results and discussion. All authors read and approved the final manuscript.

Funding

This work was financially supported by the National Science Foundation of China (No. 21565001).

\section{Availability of data and materials}

All data and material analyzed or generated during this investigation are included in this published article.

\section{Competing interests}

The authors declare that they no competing interests. 


\section{Author details}

${ }^{1}$ School of Chemistry and Chemical Engineering, North Minzu University, Yinchuan 750021, People's Republic of China. ${ }^{2}$ No. 204 Wenchang North Street, Xixia District, Yinchuan, People's Republic of China.

Received: 14 May 2019 Accepted: 24 December 2019

Published online: 14 January 2020

\section{References}

1. Dimitrios B, Abuzar K, Marcello L et al (2018) Food sample preparation for the determination of sulfonamides by high-performance liquid chromatography:state-of-the-Art. Separations 5(2):31. https://doi. org/10.3390/separations5020031

2. Wegst-Uhrich SR, Navarro DA, Zimmerman L et al (2014) Assessing antibiotic sorption in soil: a literature review and new case studies on sulfonamides and macrolides. Chem Centl J 8(1):5. https://doi. org/10.1186/1752-153X-8-5

3. Stahl J, Zessel K, Schulz J et al (2016) The effect of miscellaneous oral dosage forms on the environmental pollution of sulfonamides in pig holdings. BMC Vet Res 12(1):68. https://doi.org/10.1186/s12917-016-0688-6

4. Stoob K, Singer HP, Mueller SR et al (2007) Dissipation and transport of veterinary sulfonamide antibiotics after manure application to grassland in a small catchment. Environ Sci Tech 41(21):7349-7355. https://doi. org/10.1021/es070840e

5. Codex Alimentarius Commission (CAC): CAC/MRL02-2008, "Maximum Residue Limits for Veterinary Drugs in Food"

6. Maximum Residue Limits of Veterinary Drugs in Animal Food of the People's Republic of China (Notice No. 235 of the Ministry of Agriculture, 2002)

7. Tian Y, Gao B, Chen H et al (2013) Interactions between carbon nanotubes and sulfonamide antibiotics in aqueous solutions under various physicochemical conditions. J Environ Sci and Health Part A 48(9):11361144. https://doi.org/10.1080/10934529.2013.774670

8. Soriano-Correa C, Barrientos-Salcedo C, Francisco-Márquez Misaela et al (2018) Computational study of substituent effects on the acidity, toxicity and chemical reactivity of bacteriostatic sulfonamides. J Mol Gr Mode 81:116-124. https://doi.org/10.1016/j.jmgm.2018.02.006

9. Segura PA, Tremblay P, Picard P et al (2010) High-throughput quantitation of seven sulfonamide residues in dairy milk using laser diode thermal desorption-negative mode atmospheric pressure chemical ionization tandem mass spectrometry. J Agr Food Chem 58(3):1442-1446. https:// doi.org/10.1021/jf903362v

10. Ji L, Chen W, Zheng S et al (2009) Adsorption of sulfonamide antibiotics to multiwalled carbon nanotubes. Langmuir 25(19):11608-11613. https:// doi.org/10.1021/la9015838

11. Yang W, Zheng F, Xue X et al (2011) Investigation into adsorption mechanisms of sulfonamides onto porous adsorbents. J Colloid Interf Sci 362(2):503-509. https://doi.org/10.1016/j.jcis.2011.06.071

12. Nurmi L, Holappa S, Mikkonen H et al (2007) Controlled grafting of acetylated starch by atom transfer radical polymerization of MMA. Eur Polym J 43(4):1372-1382. https://doi.org/10.1016/j.eurpolymj.2007.01.038

13. Morandi G, Heath L, Thielemans W (2009) Cellulose nanocrystals grafted with polystyrene chains through surface-initiated atom transfer radical polymerization (SI-ATRP). Langmuir 25(14):8280-8286. https://doi. org/10.1021/la900452a

14. Coad BR, Lu Y, Meagher $L$ (2012) A substrate-independent method for surface grafting polymer layers by atom transfer radical polymerization: reduction of protein adsorption. Acta Biomater 8(2):608-618. https://doi. org/10.1016/j.actbio.2011.10.006

15. Niu L, Deng S, Yu G et al (2010) Efficient removal of $\mathrm{Cu}(\mathrm{II}), \mathrm{Pb}(\mathrm{II}), \mathrm{Cr}(\mathrm{VI})$ and $\mathrm{As}(\mathrm{V})$ from aqueous solution using an aminated resin prepared by surface-initiated atom transfer radical polymerization. Chem Eng J 165(3):751-757. https://doi.org/10.1016/j.cej.2010.08.053

16. Chen Y, Zhao W, Zhang J (2017) Preparation of 4-vinylpyridine (4-VP) resin and its adsorption performance for heavy metal ions. RSC Adv 7(8):4226-4236. https://doi.org/10.1039/C6RA26813G
17. Huang X, Xu C, Ma J et al (2018) lonothermal synthesis of Cu-doped $\mathrm{Fe}_{3} \mathrm{O}_{4}$, magnetic nanoparticles with enhanced peroxidase-like activity for organic wastewater treatment. Adv Powder Tech. https://doi. org/10.1016/j.apt.2017.12.025

18. Liu T, Chang G, Cao R et al (2015) Applications of superparamagnetic $\mathrm{Fe}_{3} \mathrm{O}_{4}$ nanoparticles in magnetic resonance imaging. Prog Chem 27(5):601-613. https://doi.org/10.7536/PC141042

19. Jin Y-Y, Cheng W, Wang M et al (2014) Preparation and characterization of monodisperse carboxylated $\mathrm{Fe}_{3} \mathrm{O}_{4}$ magnetic nanoparticles. Chinese Sci Bull 18:1700-1706. https://doi.org/10.1360/972013-663

20. Cheng Y, Xiao Z-G, Yu H-W et al (2017) Preparation and adsorption properties of aminoation modified mesoporous $\mathrm{Fe}_{3} \mathrm{O}_{4} @ \mathrm{SiO}_{2} @$ $\mathrm{mSiO}_{2}$ magnetic adsorbent. Funct Mater. https://doi.org/10.3969/j. issn.1001-9731.2017.12.024

21. Liu Q-S, Zheng T, Wang P et al (2010) Adsorption isotherm, kinetic and mechanism studies of some substituted phenols on activated carbon fibers. Chem Eng J 157(2-3):348-356. https://doi.org/10.1016/j. cej.2009.11.013

22. Ma M-H, Niu Y-L, Gong Y-R et al (2014) Preparation of 2,4-dichlorophenoxyacetic acid molecularly imprinted polymer based on surface-initiated atom transfer radical polymerization and its recognition characteristics. J Agr Pharm. https://doi.org/10.3969/j.issn.1008-7303.2014.02.09

23. Khattab TA, Kassem NF, Adel AM et al (2019) Optical recognition of ammonia and amine vapor using "turn-on" fluorescent chitosan nanoparticles imprinted on cellulose strips. J Fluoresc. https://doi.org/10.1007/ s10895-019-02381-5

24. Jia X, Xu M, Wang Y et al (2013) Polydopamine-based molecular imprinting on silica-modified magnetic nanoparticles for recognition and separation of bovine hemoglobin. Analyst 138(2):651-658. https://doi. org/10.1039/c2an36313e

25. Wu Q, Li M, Huang Z et al (2018) Well-defined nanostructured core-shell magnetic surface imprinted polymers $\left(\mathrm{Fe}_{3} \mathrm{O}_{4} @ \mathrm{SiO}_{2} @ \mathrm{MIPs}\right)$ for effective extraction of trace tetrabromobisphenol A from water. J Ind Eng Chem 60:268-278. https://doi.org/10.1016/j.jiec.2017.11.013

26. Xie S, Li J-Y, Zhao Q-X (2012) Study on adsorption process of activated carbon from sulfonamides. J Environ Eng-asce 06(2):483-488

27. Ji Y-X (2013) Adsorption characteristics of rice hull ash on antibiotic sulfonamide. Environ sci 34(10):3912-3920

28. Bao X-L, Qiang Z-M, Qi W-W et al (2013) Adsorption and removal of sulfonamides in water by magnetic nanocomposites $\mathrm{CoFeM}_{48}$. J Environ Sci 33(2):401-407

29. Piccin JS, Dotto GL, Vieira MLG et al (2011) Kinetics and mechanism of the food dye $\mathrm{fd} \& \mathrm{c}$ red 40 adsorption onto chitosan. J Chem Eng Data 56(10):3759-3765. https://doi.org/10.1021/je200388s

30. Kumar YP, King P, Prasad VSRK (2006) Comparison for adsorption modelling of copper and zinc from aqueous solution by Ulva fasciata sp. J Hazard Mater 137(2):1246-1251. https://doi.org/10.1016/j.jhazm at.2006.04.018

31. Du B-B, Xu Y, Huang Y-H (2012) Determination of sulfonamides in feed by molecularly imprinted solid phase extraction-high performance liquid chromatography. Anal Chem 40(12):1871-1876. https://doi.org/10.3724/ SP.J.1096.2012.20161

32. Liu B-Y, Yao Z, Zhou Z et al (2009) Adsorption kinetics and thermodynamics of chelating resins for copper ions. J Process Eng 9(5):865-870. https:// doi.org/10.3321/j.issn:1009-606X.2009.05.006

33. Kililç M, Yazilcil H, Solak M (2009) Comprehensive study on removal and recovery of copper(II) from aqueous solutions by $\mathrm{NaOH}$-pretreated Marrubium globosum ssp. globosum leaves powder: potential for utilizing the copper(II) condensed desorption solutions in agricultural applications. Bioresour Technol 100(7):2130-2137. https://doi.org/10.1016/j.biort ech.2008.11.002

\section{Publisher's Note}

Springer Nature remains neutral with regard to jurisdictional claims in published maps and institutional affiliations. 